\title{
Longitudinal MRI Reveals Altered Trajectory of Brain Development during Childhood and Adolescence in Fetal Alcohol Spectrum Disorders
}

\author{
Sarah Treit, ${ }^{1}$ Catherine Lebel, ${ }^{2}$ Lauren Baugh, ${ }^{2}$ Carmen Rasmussen, ${ }^{1,3}$ Gail Andrew, ${ }^{3,4}$ and Christian Beaulieu ${ }^{1,2}$ \\ ${ }^{1}$ Centre for Neuroscience, ${ }^{2}$ Department of Biomedical Engineering, ${ }^{3}$ Department of Pediatrics, University of Alberta, Edmonton, Alberta, Canada, T6G 2V2, \\ and ${ }^{4}$ FASD Clinic, Glenrose Rehabilitation Hospital, Edmonton, Alberta, Canada, T5B 0B7
}

Diffusion tensor imaging (DTI) of brain development in fetal alcohol spectrum disorders (FASD) has revealed structural abnormalities, but studies have been limited by the use of cross-sectional designs. Longitudinal scans can provide key insights into trajectories of neurodevelopment within individuals with this common developmental disorder. Here we evaluate serial DTI and T1-weighted volumetric MRI in a human sample of 17 participants with FASD and 27 controls aged 5-15 years who underwent 2-3 scans each, $\sim 2-4$ years apart (92 scans total). Increases of fractional anisotropy and decreases of mean diffusivity (MD) were observed between scans for both groups, in keeping with changes expected of typical development, but mixed-models analysis revealed significant age-by-group interactions for three major white matter tracts: superior longitudinal fasciculus and superior and inferior fronto-occipital fasciculus. These findings indicate altered developmental progression in these frontal-association tracts, with the FASD group notably showing greater reduction of MD between scans. $\triangle \mathrm{MD}$ is shown to correlate with reading and receptive vocabulary in the FASD group, with steeper decreases of MD in the superior fronto-occipital fasciculus and superior longitudinal fasciculus between scans correlating with greater improvement in language scores. Volumetric analysis revealed reduced total brain, white, cortical gray, and deep gray matter volumes and fewer significant age-related volume increases in the FASD group, although age-by-group interactions were not significant. Longitudinal DTI indicates delayed white matter development during childhood and adolescence in FASD, which may underlie persistent or worsening behavioral and cognitive deficits during this critical period.

\section{Introduction}

Fetal alcohol spectrum disorders (FASD) describe a range of physical, cognitive, and behavioral deficits stemming from prenatal alcohol exposure. Despite increased awareness of the teratogenic effects of alcohol since their recognition in the 1970s, FASD has an estimated prevalence of $\sim 1$ in 100 and represents the leading cause of preventable developmental disability in North America (May and Gossage, 2001; May et al., 2009). Alcohol negatively impacts the developing brain through numerous mechanisms including altered gene transcription, neuronal proliferation, and migration errors, oxidative stress, hypoxia, and cell death (for review, see Goodlett et al., 2005). Resulting impairments vary widely between individuals, depending on timing and

\footnotetext{
Received 0ct. 25, 2012; revised April 15, 2013; accepted May 9, 2013.

Author contributions:S.T., C.L., C.R., G.A., and C.B. designed research;S.T., C.L., and L.B. performed research;S.T. analyzed data; S.T. and C.B. wrote the paper.

This work was funded by the Canadian Institutes of Health Research (CIHR) and the Network of Centres of Excellence Canadian Language and Literacy Research Network (CLLRNet). Alberta Innovates-Health Solutions, CIHR, and the Natural Sciences and Engineering Council (NSERC) provided salary support. We gratefully acknowledge the contributions of Katy Wyper, Anna Matejko, and Olivia Jaswal (for cognitive testing at time 1), as well as the 44 participants and their parents and caregivers who donated their time and efforts for this work.

The authors declare no competing financial interests.

Correspondence should be addressed to Dr Christian Beaulieu, Department of Biomedical Engineering, Faculty of Medicine and Dentistry, 1098 Research Transition Facility, University of Alberta, Edmonton, Alberta, Canada T6G2V2. E-mail: christian.beaulieu@ualberta.ca.

DOI:10.1523/JNEUROSCI.5004-12.2013

Copyright $\odot 2013$ the authors $\quad 0270-6474 / 13 / 3310098-12 \$ 15.00 / 0$
}

quantity of exposure and the likely interaction of a host of environmental and genetic factors. Although physical and medical complications vary, neurobehavioral deficits are characteristic of the entire spectrum of FASD, and are considered to be the most functionally debilitating (Mattson et al., 1998).

Advanced brain imaging studies of FASD have revealed abnormalities in brain volume, microstructure, cortical thickness, metabolism, and functional activation (for review, see Roussotte et al., 2010). One of the most robust findings is reduced brain volume, with many studies reporting reduced total brain, gray and white matter, as well as numerous deep gray matter volumes, with some reductions persisting after controlling for total brain volume (Astley et al., 2009a; Lebel et al., 2011). Diffusion tensor imaging (DTI) studies of children with FASD have revealed microstructural abnormalities in the corpus callosum, cingulum, cortico-spinal tracts, cerebellar peduncles, and a number of association fibers (Wozniak et al., 2006, 2009; Lebel et al., 2008b; Sowell et al., 2008; Fryer et al., 2009; Spottiswoode et al., 2011). Brain volume (Coles et al., 2011) and DTI abnormalities (Ma et al., 2005; Li et al., 2009) also persist in adult subjects with FASD. Although DTI studies have greatly advanced our understanding of brain pathology in FASD, they have all been cross-sectional in design, limiting conclusions about brain development.

Longitudinal studies of healthy development have confirmed increases of white matter, decreases of cortical gray matter, and various changes to deep gray matter volumes during childhood 


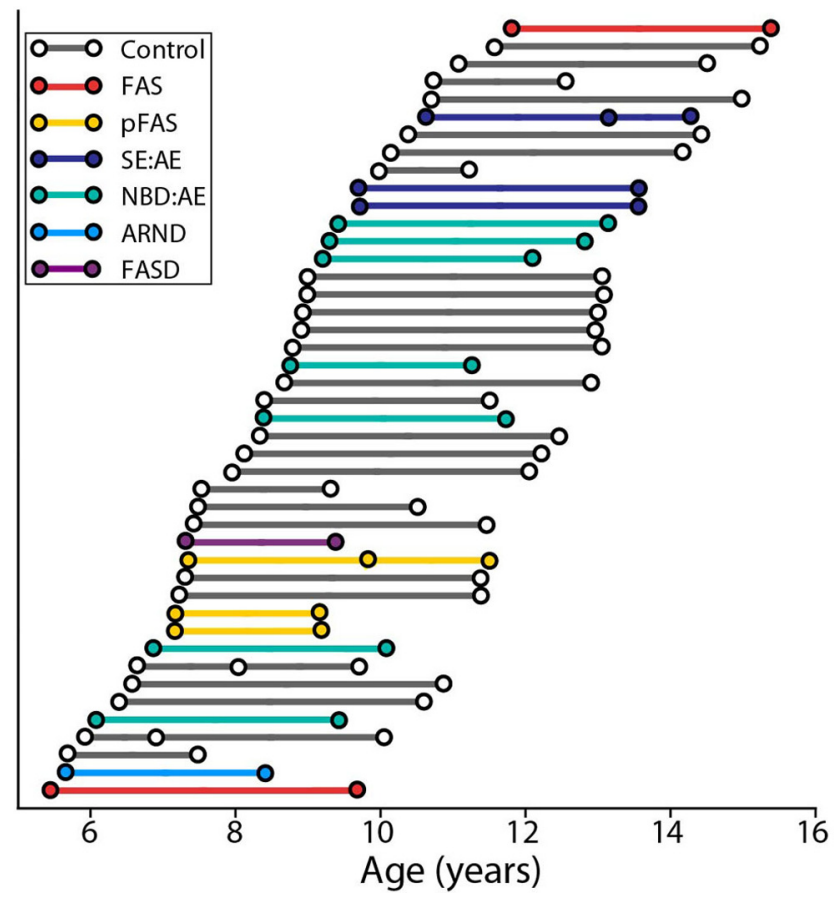

Figure 1. Age and time between scans by diagnosis. Circles represent each scan, connecting lines represents the time between scans for each participant, and colors indicate diagnostic subgroups under the FASD umbrella versus controls (shown in gray). Forty participants had two scans each and four participants had three scans each for a total of 92 scans, $\sim 2-4$ years apart.

and adolescence (Giedd et al., 1999; Lenroot et al., 2007), in concert with underlying progressive and regressive cellular events. Likewise, increases of fractional anisotropy (FA) and reductions of mean diffusivity (MD) of white matter have been observed in longitudinal DTI studies of healthy children and adolescents (Bava et al., 2010; Giorgio et al., 2010; Lebel and Beaulieu, 2011), and are presumed to reflect reduced water content, increased myelination and/or increased coherence/packing of axons within white matter tracts. One recent longitudinal volume study has shown altered trajectories of cortical volume growth in FASD, but did not include DTI (Lebel et al., 2012). To better understand how brain abnormalities evolve during these key developmental periods of behavioral and cognitive progression, this study aims to examine for the first time within-subject longitudinal changes in white matter DTI parameters in FASD during childhood and adolescence.

\section{Materials and Methods}

Subjects. Participants were 17 children with FASD (11 males, 6 females; $5.4-11.8$ years of age at first scan) and 27 control participants ( 15 males, 12 females; 5.7-11.1 years of age at first scan); all scanned $1.8-4.2$ years apart (Fig. 1; Table 1). Fourteen of 17 FASD scan 1 data were included in our cross-sectional DTI study (Lebel et al., 2008b), 9 of these 14 were also included in our cross-sectional deep gray matter volumetric study (Nardelli et al., 2011), and all control participant scans were a subset from our previous longitudinal study of healthy brain development (Lebel and Beaulieu, 2011). A total of 92 scans were collected: 15 subjects with FASD and 25 controls with two scans each; two subjects with FASD and two controls with three scans each. FASD participants were recruited from a hospital FASD diagnostic clinic, had confirmed prenatal alcohol exposure and were previously medically diagnosed with an alcohol related disorder falling under the FASD umbrella in accordance with the Canadian Guidelines for diagnosis of FASD (Chudley et al., 2005) and the 4-digit code (Astley, 2004). In addition, two subjects with FASD were recruited from a community clinic and were diagnosed under the Institute of Medicine guidelines (Hoyme et al., 2005). Two subjects had a diagnosis of fetal alcohol syndrome (FAS), three partial FAS (pFAS), three static encephalopathy alcohol exposed (SE:AE), seven neurobehavioral disorder alcohol exposed (NBD:AE), one alcohol related neurobehavioral disorder (ARND), and one FASD that was not further specified. Given the small number of subjects, all subdiagnoses were collapsed to form one FASD group for statistical analysis, but are represented separately in several figures. Control subjects were screened for psychiatric and neurological impairments, as well as contraindications to MRI. In addition, control subjects' caregivers were contacted retrospectively (at the time of data analysis for this paper) and asked to estimate in utero alcohol exposure for their child. Of the 21 control subject caregivers who were reached, 14/21 reported no exposure, 2/21 unknown, and 5/21 reported minimal alcohol exposure (range: $1-3$ drinks; average of two drinks total during pregnancy). Written informed consent was obtained from all participants' parent/legal guardian, and written assent was collected from all participants before study procedures. This study was approved by the Health Research Ethics Board at the University of Alberta.

Cognitive testing and demographics. Participants with FASD underwent $\sim 1.5 \mathrm{~h}$ of cognitive testing at each scan, administered by a trained research assistant. The test battery included the Woodcock Johnson Quantitative Concepts 18A\&B (mathematics), Woodcock Reading Mastery Test-Revised (WRMT-R) Word ID, Comprehensive Expressive and Receptive Vocabulary Test (CREVT), Working Memory Test Battery for Children (WMTB-C), Behavior Rating Inventory of Executive Function (BRIEF) parent form, and NEPSYI/II (auditory attention and response set; memory for names, narrative memory; arrows). The NEPSY I was administered at scan 1 but subsequently updated to NESPY II by scan 2; therefore only subtests that did not change in the new edition are included here. In addition, nine participants in the FASD group were administered the Wide Range Intelligence Test (WRIT) at scan 2. Given that control data were previously collected for a study of healthy development, control subjects did not undergo a full battery of cognitive testing, but were administered WRMT-R Word ID at each scan. Demographic information (Table 1) was collected via questionnaire given to participants' caregivers at scan 2 for the FASD group, and retrospectively by phone interview for controls.

Image acquisition. All data at both time-points were acquired using identical methods, hardware and sequence parameters on the same 1.5T Siemens Sonata MRI scanner. Scans included DTI, T1-weighted, T2weighted, fluid-attenuated inversion recovery (FLAIR), and FLAIR-DTI (not used here) for a total scan time of $\sim 26 \mathrm{~min}$. DTI was acquired using a dual spin-echo, single shot echo-planar imaging sequence with: 403 $\mathrm{mm}$ axial-oblique slices with no interslice gap; $\mathrm{TR}=6400 \mathrm{~ms}$; $\mathrm{TE}=88$ $\mathrm{ms} ; 6$ noncollinear diffusion sensitizing gradient directions with $\mathrm{b}=$ $1000 \mathrm{~s} / \mathrm{mm}^{2} ; 8$ averages; FOV $=220 \times 220 \mathrm{~mm}^{2}$; matrix of $128 \times 128$ with $75 \%$ phase partial Fourier zero-filled to $256 \times 256$ for a total acquisition time of 6:06 min. T1-weighted images for volume analysis were acquired using a high resolution $\left(1 \times 1 \times 1 \mathrm{~mm}^{3}\right)$ MPRAGE sequence with: TR $=1870 \mathrm{~ms}, \mathrm{TE}=4.38 \mathrm{~ms}$, TI $=1100 \mathrm{~ms}$ for a total acquisition of 4:29 min. Three FASD and two control participants at scan 1, and one (different) control at scan 2 are missing MPRAGE data because they were either unable to tolerate the full-length of scan, or moved too much to obtain adequate data. In addition, three FASD and six control MPRAGE data were acquired without including the top of cortex at scan 1 , and were therefore excluded from volume analysis, leaving 11 FASD and 18 control subjects. By necessity, all subjects included here had successful DTI at both scans.

Tractography. A previously described semiautomated tractography method (Lebel et al., 2008a) was used to delineate 11 major white matter tracts for each scan. Subject images were normalized to a template using a nonaffine transformation, saving warping parameters for each subject. Seed, target, and exclusion regions were drawn on the template according to a priori information on tract location (Wakana et al., 2004), and then applied to each subject's native color map using an inverse of their normalization parameters, such that the same seed, target, and exclusion regions were applied to all subjects. White matter tracts included the genu (gCC), body (bCC), and splenium (sCC) of the corpus callosum, the anterior limb of the internal capsule (ALIC), corticospinal tracts (CST), superior and inferior longitudinal fasciculus (SLF; ILF), superior 
Table 1. Participant characteristics and demographics for FASD and control groups

\begin{tabular}{|c|c|c|c|}
\hline & FASD & Control & $p$ value $^{c}$ \\
\hline Participant characteristics & $n=17$ & $n=27$ & \\
\hline Mean age 1st scan (years) & $8.2 \pm 1.8(5.4-11.8)$ & $8.5 \pm 1.6(5.7-11.6)$ & ns \\
\hline Mean age last scan (years) & $11.4 \pm 2.1(8.4-15.3)$ & $12.0 \pm 1.8(7.4-15.2)$ & ns \\
\hline Mean time between scans (years) & $3.2 \pm 0.7(2.0-4.2)$ & $3.6 \pm 0.9(1.2-4.2)$ & ns \\
\hline No. males (\%) & $11(65)$ & $15(56)$ & ns \\
\hline No. right handed (\%) & $13(76)$ & $26(96)$ & 0.046 \\
\hline Demographics & $n=16^{a}$ & $n=21$ & \\
\hline \multicolumn{4}{|l|}{ Ethnicity (\%) } \\
\hline Caucasian & $8(47)$ & $20(95)$ & 0.001 \\
\hline Aboriginal & $8(53)$ & $0(0)$ & $<0.001$ \\
\hline Other & $0(0)$ & $1(5)$ & ns \\
\hline Median annual household income & $\$ 76,000-\$ 100,000$ & $\$ 76,000-100,000$ & ns \\
\hline \multicolumn{4}{|l|}{ Caregiver status (\%) } \\
\hline Biological parent(s) & $0(0)$ & $21(100)$ & $<0.001$ \\
\hline Adopted & $9(53)$ & $0(0)$ & $<0.001$ \\
\hline Foster & $4(29)$ & $0(0)$ & 0.017 \\
\hline Biological relative & $3(18)$ & $0(0)$ & 0.41 \\
\hline $\begin{array}{l}\text { Mean number of foster care placements per child } \\
\text { Comorbidities (\%) }\end{array}$ & 1.4 & 0.0 & $<0.001$ \\
\hline ADHD & $11(65)$ & $1(5)^{b}$ & $<0.001$ \\
\hline Oppositional Defiant Disorder & $4(24)$ & $0(0)$ & 0.017 \\
\hline Anxiety & $5(29)$ & $0(0)$ & 0.007 \\
\hline Other & $6(35)$ & $0(0)$ & 0.002 \\
\hline \multicolumn{4}{|l|}{ Psychoactive medications (\%) } \\
\hline Atypical Antipsychotic & $11(65)$ & $0(0)$ & $<0.001$ \\
\hline Psycho-stimulant & $10(59)$ & $0(0)$ & $<0.001$ \\
\hline Antidepressant & $5(29)$ & $0(0)$ & 0.007 \\
\hline Other & $3(18)$ & $0(0)$ & 0.043 \\
\hline Average number per subject & 1.9 & 0 & $<0.001$ \\
\hline
\end{tabular}

${ }^{a}$ Demographic information was collected at the second scan for FASD group but retrospectively by phone questionnaire for controls; demographic data was not collected for one FASD subject, and six control subjects were lost to follow-up or did not return phone calls.

${ }^{b}$ Parent-reported (diagnosis not confirmed); not medicated at time of MRI.

'Group differences in categorical variables (e.g. gender) assessed with Mann-Whitney U; continuous variables (e.g., age) tested with independent sample $t$ test (at $p<0.05$ ).

and inferior fronto-occipital fasciculus (SFO; IFO), cingulum, and uncinate fasciculus (UF). Tractography was performed in native space for each subject, using a deterministic streamline method in ExploreDTI (Leemans et al., 2009), and fibers in the left and right hemisphere were measured separately at this stage for all tracts except the corpus callosum. A minimum FA threshold of 0.25 was used to initiate and continue tracking, and an angle threshold of $60^{\circ}$ was set for the UF and SLF and $30^{\circ}$ for all other tracts. Deterministic tractography robustly reconstructs major white matter tracts, but can lead to errors in areas with crossing fibers (e.g., the intersection of the corpus callosum and cortico-spinal tracts) where intersecting fibers within a voxel can make it difficult to determine a primary diffusion orientation, artificially lowering FA and in some cases terminating tracking. All tracts were manually inspected for consistency with known anatomy. Minor manual modifications were made to $\sim 20 \%$ of tracts to exclude spurious fibers. Adequate tracking was not achieved in $3 \%$ of tracts (e.g., very small number of streamlines), and these were excluded from the analysis. FA and MD were measured for each tract by averaging all voxels of a tract, counting each voxel only once (i.e., FA/MD in a given voxel was not weighted by number of streamlines). Similarly, parallel $\left(\lambda_{/ /}=\lambda_{1}\right)$ and perpendicular $\left[\lambda_{\perp}=\left(\lambda_{2}+\lambda_{3}\right) / 2\right]$ diffusivities were calculated for each tract. FA or MD of left and right counterparts of all bilateral tracts were significantly correlated (i.e., left FA versus right FA, left $\mathrm{MD}$ versus right $\mathrm{MD}, R$ values ranging from 0.31 to 0.88 , mean 0.69 ; $p<0.001$ to $p=0.003$ ), so to reduce the number of multiple-comparisons and streamline the data presentation, diffusion parameters of corresponding left and right tracts were averaged before statistical analysis.

Volume analysis. T1-weighted MPRAGE images were processed using Freesurfer version 4.1.0 (Anthinoula A. Martinos Center for Biomedical Imaging). An automated processing pipeline (Fischl et al., 2002) was used to extract volumes for total brain (excluding CSF and cerebellum), white matter, cortical gray matter, as well as bilateral hippocampus, amygdala, thalamus, caudate, putamen, and globus pallidus. All segmen- tations were visually inspected for accuracy. Corresponding left and right deep gray matter structure volumes were significantly correlated $(r=$ $0.83-0.94$; mean $0.90 p<0.001$ for all structures) so left and right counterparts of bilateral structures were averaged before statistical analysis to reduce multiple-comparisons.

Statistical analysis. One-sample $t$ tests were used to compare cognitive test standard scores with population norms (standard score of 100 for all tests except NEPSY scaled score of 10 and BRIEF T scores of 50). Pairedsample $t$ tests were used to determine whether there was a change in standard score from scan 1 to scan 2 for each test (at $p<0.05$ ).

The effect of age, group, and age-by-group interactions of FA, MD, and volumes were assessed using a linear mixed-model with the following equation: dependent variable (DTI parameter or volume) $=$ Intercept $+\mathrm{A}^{\star}$ age $+\mathrm{B}^{\star}$ group $+\mathrm{C}^{\star}$ gender $+\mathrm{D}^{\star}$ age $\times$ group + residual. This statistical approach was chosen for its ability to handle datasets with repeated-measures and varying intervals between measurements. For tractography analysis, a main effect of gender on FA or MD was only significant $(p<0.05)$ for FA of the ALIC $(p=0.001)$ and SLF $(p=$ $0.031)$, and both FA and MD of the genu ( $p=0.004$ and $p=0.015$, respectively); therefore, gender was subsequently removed from the model before testing age-by-group interactions for all other tracts. A main effect of gender on volume was significant $(p<0.05)$ for all structures and therefore included in the model for all volumetric analyses. Significant age-by group interactions $(p<0.05)$ of DTI parameters were followed up with two additional analyses: (i) parallel and perpendicular diffusivities were tested using the same model to help determine underlying factors driving FA and MD changes, and (ii) the relationship between brain development and cognition was tested using partial correlations of $\Delta \mathrm{FA}$ or $\Delta \mathrm{MD}$ (see calculation below) and $\Delta$ raw cognitive scores (raw score ${ }_{2}-$ raw score ${ }_{1}$ ), controlling for mean age and time between scans. Partial correlations were also used to test the relationship between $\Delta$ volume and $\Delta$ raw cognitive score for total brain volume, white 
Table 2. Cognitive testing in FASD group showing below average standard scores (age normalized) on most tests, but no significant differences in standard scores between longitudinal scans

\begin{tabular}{|c|c|c|c|c|c|c|}
\hline Cognitive test & Subtest/domain & Scan & $N(17)$ & $\begin{array}{l}\text { Mean } \\
\text { standard } \\
\text { score } \pm S D\end{array}$ & $\begin{array}{l}\text { Standard } \\
\text { score } \\
\text { range }\end{array}$ & $\begin{array}{l}\text { One sample } t \\
\text { test } p \text { value }^{a}\end{array}$ \\
\hline \multirow{4}{*}{$\begin{array}{l}\text { Working memory test battery for } \\
\text { children }\end{array}$} & \multirow[t]{2}{*}{ Digit recall } & 1 & 16 & $86 \pm 13$ & $60-111$ & 0.001 \\
\hline & & 2 & 17 & $88 \pm 14$ & $52-117$ & 0.002 \\
\hline & \multirow[t]{2}{*}{ Block recall } & 1 & 16 & $83 \pm 16$ & $57-108$ & 0.001 \\
\hline & & 2 & 17 & $83 \pm 15$ & $59-110$ & $<0.001$ \\
\hline \multirow[t]{2}{*}{ Woodcock Johnson } & \multirow{2}{*}{$\begin{array}{l}\text { Quantitative Concepts 18A\&B } \\
\text { (mathematics) }\end{array}$} & 1 & 16 & $90 \pm 16$ & $62-115$ & 0.019 \\
\hline & & 2 & 15 & $90 \pm 10$ & $70-107$ & 0.002 \\
\hline \multirow{6}{*}{$\begin{array}{l}\text { Comprehensive receptive and ex- } \\
\text { pressive vocabulary test (CREVT) }\end{array}$} & \multirow[t]{2}{*}{ Receptive } & 1 & 16 & $91 \pm 7$ & $75-102$ & $<0.001$ \\
\hline & & 2 & 16 & $92 \pm 8$ & $74-102$ & 0.001 \\
\hline & \multirow[t]{2}{*}{ Expressive } & 1 & 16 & $84 \pm 16$ & $63-112$ & 0.001 \\
\hline & & 2 & 16 & $82 \pm 14$ & 57-107 & $<0.001$ \\
\hline & \multirow[t]{2}{*}{ Composite } & 1 & 16 & $85 \pm 11$ & $68-106$ & $<0.001$ \\
\hline & & 2 & 16 & $84 \pm 12$ & $62-102$ & $<0.001$ \\
\hline \multirow{2}{*}{$\begin{array}{l}\text { Woodcock reading mastery } \\
\text { test-revised }\end{array}$} & \multirow[t]{2}{*}{ Word ID } & 1 & 17 & $93 \pm 10$ & $75-109$ & 0.011 \\
\hline & & 2 & 17 & $92 \pm 17$ & $52-134$ & 0.083 \\
\hline \multirow[t]{10}{*}{ NEPSY I/II } & \multirow[t]{2}{*}{ Arrows (visuospatial ability) } & 1 & 12 & $7.9 \pm 2.9$ & $2-12$ & 0.030 \\
\hline & & 2 & 15 & $10.2 \pm 2.8$ & $5-15$ & 0.787 \\
\hline & \multirow[t]{2}{*}{ Auditory attention (sustained attention) } & 1 & 14 & $5.3 \pm 4.0$ & $1-13$ & 0.001 \\
\hline & & 2 & 14 & $7.4 \pm 3.2$ & $1-12$ & 0.010 \\
\hline & \multirow[t]{2}{*}{ Response set (set shifting) } & 1 & 11 & $6.1 \pm 3.7$ & $2-14$ & 0.005 \\
\hline & & 2 & 14 & $8.6 \pm 3.0$ & $1-13$ & 0.109 \\
\hline & \multirow[t]{2}{*}{ Auditory attention vs response set } & 1 & 11 & $7.5 \pm 3.3$ & $4-13$ & 0.030 \\
\hline & & 2 & 14 & $9.4 \pm 3.0$ & $2-13$ & 0.434 \\
\hline & \multirow[t]{2}{*}{ Memory for names } & 1 & 12 & $8.3 \pm 3.8$ & $3-15$ & 0.134 \\
\hline & & 2 & 14 & $6.9 \pm 2.9$ & $3-12$ & 0.001 \\
\hline \multirow{6}{*}{$\begin{array}{l}\text { Behavior rating scale of executive } \\
\text { function (BRIEF) parent form }\end{array}$} & \multirow[t]{2}{*}{ Behavioral regulation index } & 1 & 15 & $75 \pm 13$ & $40-94$ & $<0.001$ \\
\hline & & 2 & 16 & $79 \pm 12$ & $50-97$ & $<0.001$ \\
\hline & \multirow[t]{2}{*}{ Metacognition index } & 1 & 15 & $71 \pm 7$ & $53-81$ & $<0.001$ \\
\hline & & 2 & 16 & $72 \pm 7$ & $55-84$ & $<0.001$ \\
\hline & \multirow[t]{2}{*}{ Global executive composite } & 1 & 15 & $74 \pm 9$ & $48-83$ & $<0.001$ \\
\hline & & 2 & 16 & $76 \pm 9$ & $53-92$ & $<0.001$ \\
\hline \multirow[t]{3}{*}{ Wide range intelligence test (WRIT) } & Verbal IQ & $2^{b}$ & 9 & $94 \pm 14$ & $75-118$ & 0.255 \\
\hline & Visual IQ & $2^{b}$ & 9 & $103 \pm 15$ & $78-122$ & 0.572 \\
\hline & General IQ & $2^{b}$ & 9 & $99 \pm 15$ & $75-116$ & 0.789 \\
\hline
\end{tabular}

${ }^{a}$ Population norm mean standard scores used as test value for one-sample $t$ test; 100 for all tests except NEPSY I/II (mean scaled score $\left.=10\right)$, and BRIEF (mean T score $=50$ ).

${ }^{b}$ The WRIT was only collected at scan 2.

matter, cortical gray matter, and all deep gray matter structures, controlling for mean age and time between scans.

In addition to mixed-models analysis, $\Delta \mathrm{FA}, \Delta \mathrm{MD}$ and $\Delta$ volume values were determined for each subject by subtracting their value at scan 1 from scan 2 for each tract or volume. For subjects with three scans, a best fit line was determined and the value at scan 1 on the line was subtracted from the value at scan 3 . A reliability study of five healthy adult subjects scanned 10 times each over a 1 week period (50 scans total) was performed to determine a measure of within-subject interscan variability (i.e., test retest variability independent of development). This substudy was performed using identical DTI and MPRAGE protocols on the same scanner, as well as the same volume segmentation and tractography methods as described above. Within-subject SDs were calculated for FA and MD of each of the 11 tracts and multiple brain volumes, and then averaged across the five subjects to produce a mean SD for each tract or structure. These mean SD values were then used as change cutoffs for $\Delta \mathrm{FA}, \Delta \mathrm{MD}$, and $\Delta$ volume values of FASD and control participants to determine the frequency of participants with increases $(>1 \mathrm{SD})$, decreases $(>1 \mathrm{SD})$ or no change $(\leq 1 \mathrm{SD})$ between scans for each group. Significant differences in the proportion of subjects in each group with increases, decreases, or no change in diffusion parameters or volumes between scans were assessed using $\chi^{2}$ analysis (at $p<0.05$ ).

\section{Results}

Cognitive testing

The FASD group performed significantly below population norm $(p<0.05)$ on all cognitive measures at both time points, with the exception of NEPSY Memory for Names at scan 1, and WRMT-R Word ID (reading), NEPSY II Arrows (visuospatial) and Response Set (set shifting) at scan 2 (Table 2). FASD group raw score values increased on all subtests between time-points, though paired-sample $t$ tests did not reveal significant changes in standard scores between scans, suggesting persistent delays relative to population norms that were not mitigated nor exacerbated with age. Results of the WRIT collected at scan 2 indicate that on average the FASD group was not significantly impaired on IQ, with a mean general IQ standard score of $99 \pm 15$; however, IQ was only tested in 53\% (9/17) of these subjects. Control group Word ID standard scores were significantly above the population norm of 100 at both scans (mean standard scores of $113 \pm 14$ at scan 1 and $111 \pm 12$ at scan 2 ), but did not show significant standard score change between scans on paired sample $t$ tests (i.e., they performed above average but changed at a rate on par with population norms).

\section{Brain volumes}

A significant effect of group $(p<0.001)$ on volume was found for all structures measured (whole brain, white matter, cortical gray matter, as well as thalamus, caudate, putamen, globus pallidus, hippocampus, and amygdala), with $7-18 \%$ reductions observed in the FASD group compared with controls (Table 3; Fig. 2). When total brain volume was added as a covariate, cortical gray 
Table 3. Effects of age, group, and age-by-group interactions for brain volumes

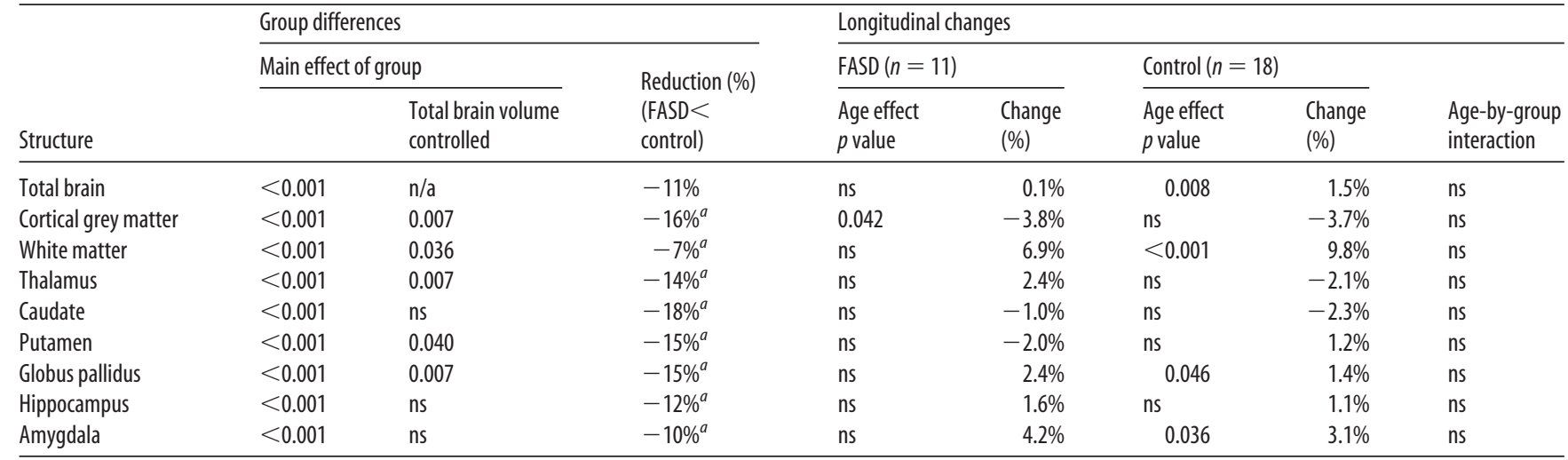

The FASD group shows smaller volumes for all structures, with many reductions persisting after controlling for total brain volume. Significant effects of age are found in several structures in the control but not FASD group, though age-by-group interactions are not significant (ns).

${ }^{a}$ Volume reduction not corrected for total brain volume.
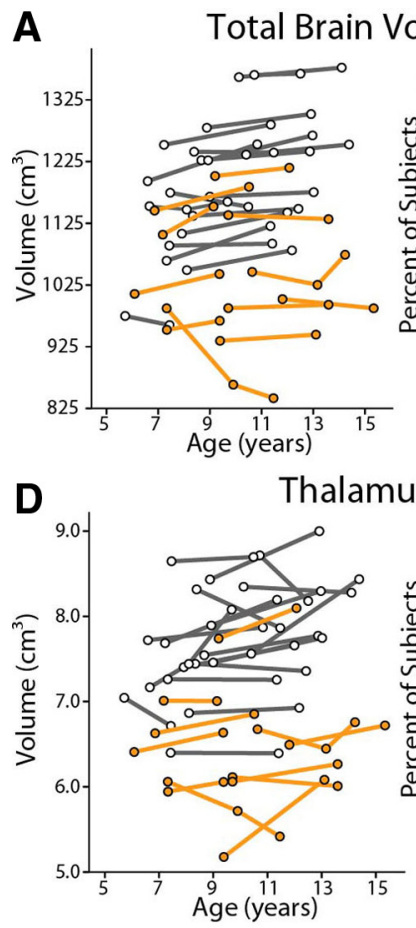

G Globus Pallidus
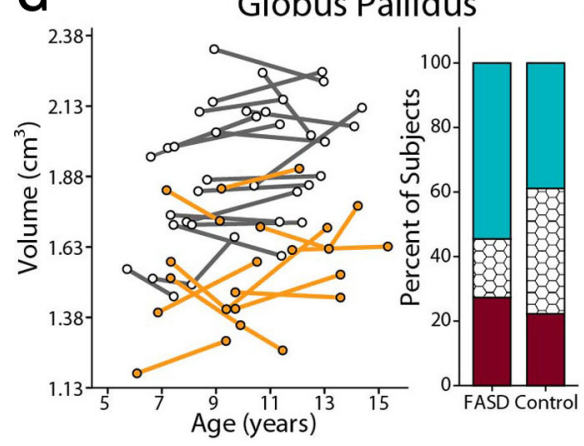
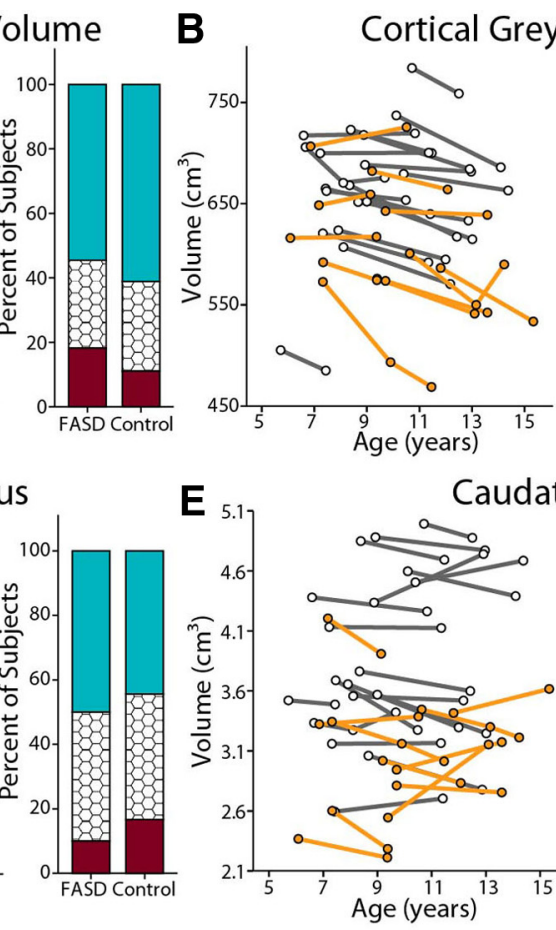

E

Caudate

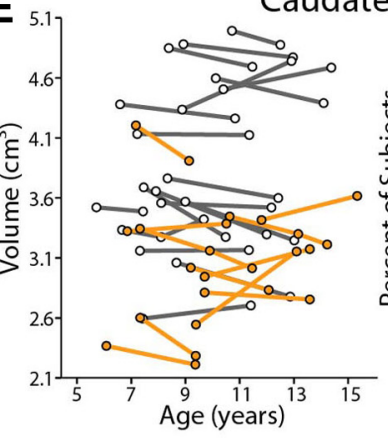

$\mathbf{H}_{5 / 5}$

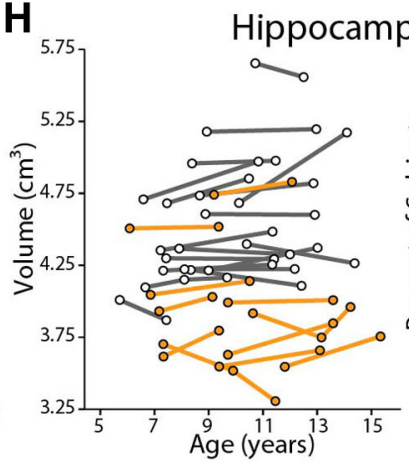

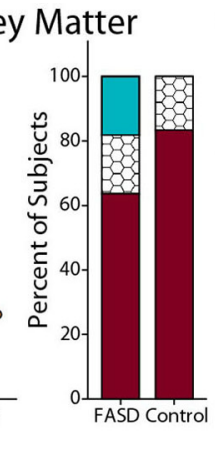

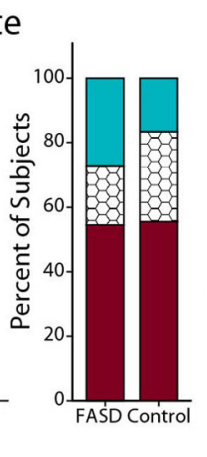

C Cerebral White Matter

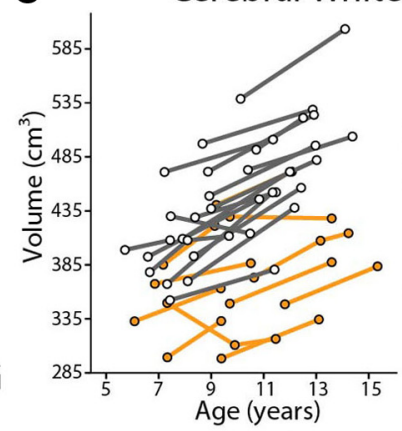

Putamen

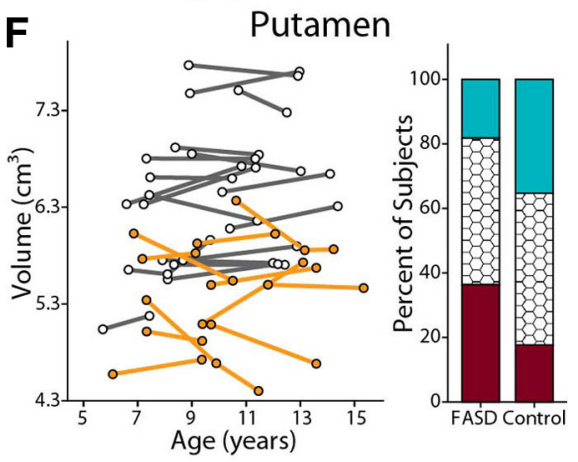

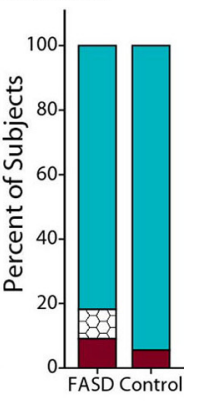

\section{$\circ \quad \circ$ FASD $\circ \circ$ Control $\square$ Volume Increase $>1$ SD 团 No Change $(<1$ SD)}

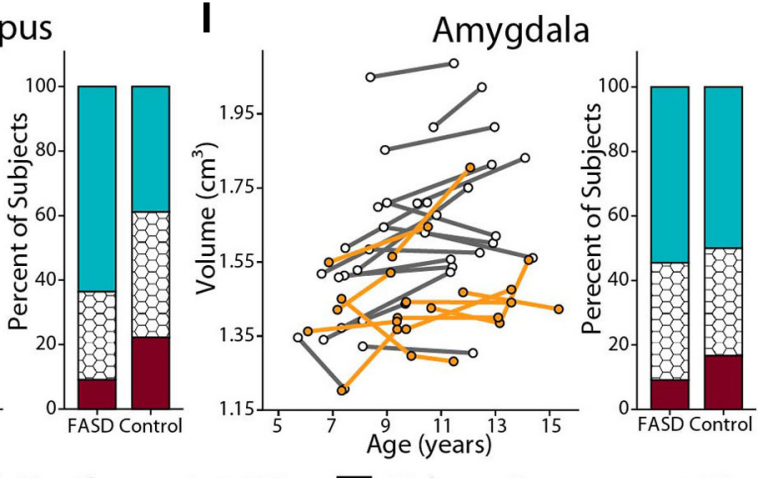

Figure 2. Changes in brain volume between scans for FASD $(n=11)$ and control subjects $(n=18)$. Significant group differences were found for all volumes ( $p<0.001)$ with the FASD group having smaller volumes than controls. After adding total brain volume as a covariate, cortical gray matter $(p=0.007)$, white matter $(p=0.036)$, thalamus $(p=0.007)$, $\operatorname{putamen}(p=0.040)$, and globus pallidus ( $p=0.007$ ) volumes remained significantly reduced. Age-by-group interactions in volume growth were not found, indicating similar trajectories of growth between groups, though significant effects of age were found in the control but not FASD group for some structures (Table 3). 
Table 4. Fractional anisotropy and mean diffusivity group and age effects between scans

\begin{tabular}{|c|c|c|c|c|c|c|c|c|c|c|c|c|}
\hline \multirow[b]{3}{*}{ Tract } & \multicolumn{6}{|c|}{ Fractional anisotropy } & \multicolumn{6}{|c|}{ Mean diffusivity $\mathrm{mm}^{2} / \mathrm{s} \times 10^{-3}$} \\
\hline & \multirow{2}{*}{$\begin{array}{l}\text { Group } \\
\text { main } \\
\text { effect }\end{array}$} & \multicolumn{2}{|l|}{ FASD } & \multicolumn{2}{|l|}{ Control } & \multirow[b]{2}{*}{$\begin{array}{l}\text { Age } \times \text { group } \\
\text { interaction }\end{array}$} & \multirow{2}{*}{$\begin{array}{l}\text { Group } \\
\text { main } \\
\text { effect }\end{array}$} & \multicolumn{2}{|l|}{ FASD } & \multicolumn{2}{|l|}{ Control } & \multirow[b]{2}{*}{$\begin{array}{l}\text { Age } \times \text { group } \\
\text { interaction }\end{array}$} \\
\hline & & $\begin{array}{l}\text { Age effect } \\
p \text { value }\end{array}$ & $\begin{array}{l}\text { Change } \\
(\%)\end{array}$ & $\begin{array}{l}\text { Age effect } \\
p \text { value }\end{array}$ & $\begin{array}{l}\text { Change } \\
(\%)\end{array}$ & & & $\begin{array}{l}\text { Age effect } \\
p \text { value }\end{array}$ & $\begin{array}{l}\text { Change } \\
(\%)\end{array}$ & $\begin{array}{l}\text { Age effect } \\
p \text { value }\end{array}$ & $\begin{array}{l}\text { Change } \\
(\%)\end{array}$ & \\
\hline Body of the corpus callosum (bCC) & ns & ns & 1.6 & 0.017 & 1.8 & ns & ns & 0.031 & -2.6 & ns & -1.6 & ns \\
\hline Genu of the corpus callosum ( $\mathrm{gCC}$ ) & ns & 0.049 & 2.2 & $<0.001$ & 2.5 & ns & 0.044 & 0.005 & -1.9 & 0.041 & -1.6 & ns \\
\hline Splenium of the corpus callosum (sCC) & ns & 0.008 & 2.5 & 0.002 & 2.7 & ns & ns & $<0.001$ & -3.9 & $<0.001$ & -3.3 & ns \\
\hline Anterior limb of the internal capsule (ALIC) & ns & $<0.001$ & 3.6 & $<0.001$ & 5.2 & ns & ns & $<0.001$ & -3.8 & $<0.001$ & -2.6 & ns \\
\hline Cortico-spinal tract (CST) & ns & $<0.001$ & 2.8 & $<0.001$ & 4.7 & ns & ns & ns & -0.2 & ns & -1.3 & ns \\
\hline Cingulum (cing) & ns & 0.004 & 3.1 & $<0.001$ & 4.3 & ns & ns & $<0.001$ & -3.4 & $<0.001$ & -2.5 & ns \\
\hline Inferior fronto-occipital fasciculus (IF0) & ns & $<0.001$ & 5.3 & $<0.001$ & 3.9 & ns & ns & $<0.001$ & -3.3 & ns & -1.2 & 0.011 \\
\hline Inferior longitudinal fasciculus (ILF) & ns & ns & 2.1 & 0.005 & 2.9 & ns & ns & $<0.001$ & -3.4 & $<0.001$ & -2.2 & ns \\
\hline Superior fronto-occipital fasciculus (SF0) & 0.015 & 0.001 & 4.1 & 0.001 & 2.9 & ns & ns & ns & -1.9 & ns & -0.7 & 0.038 \\
\hline Superior longitudinal fasciculus (SLF) & ns & 0.006 & 3.3 & $<0.001$ & 3.9 & ns & ns & $<0.001$ & -3.7 & $<0.001$ & -2.4 & 0.034 \\
\hline Uncinate fasciculus (UF) & ns & ns & 1.9 & 0.001 & 3.0 & ns & ns & $<0.001$ & -3.0 & 0.004 & -1.7 & ns \\
\hline
\end{tabular}

Age parameters are significant for most tracts in both FASD ( $n=17)$ and control subjects ( $n=27)$. Three tracts (IFO, SF0, SLF) show significant age-by-group interactions suggesting different trajectories of mean diffusivity change between groups.
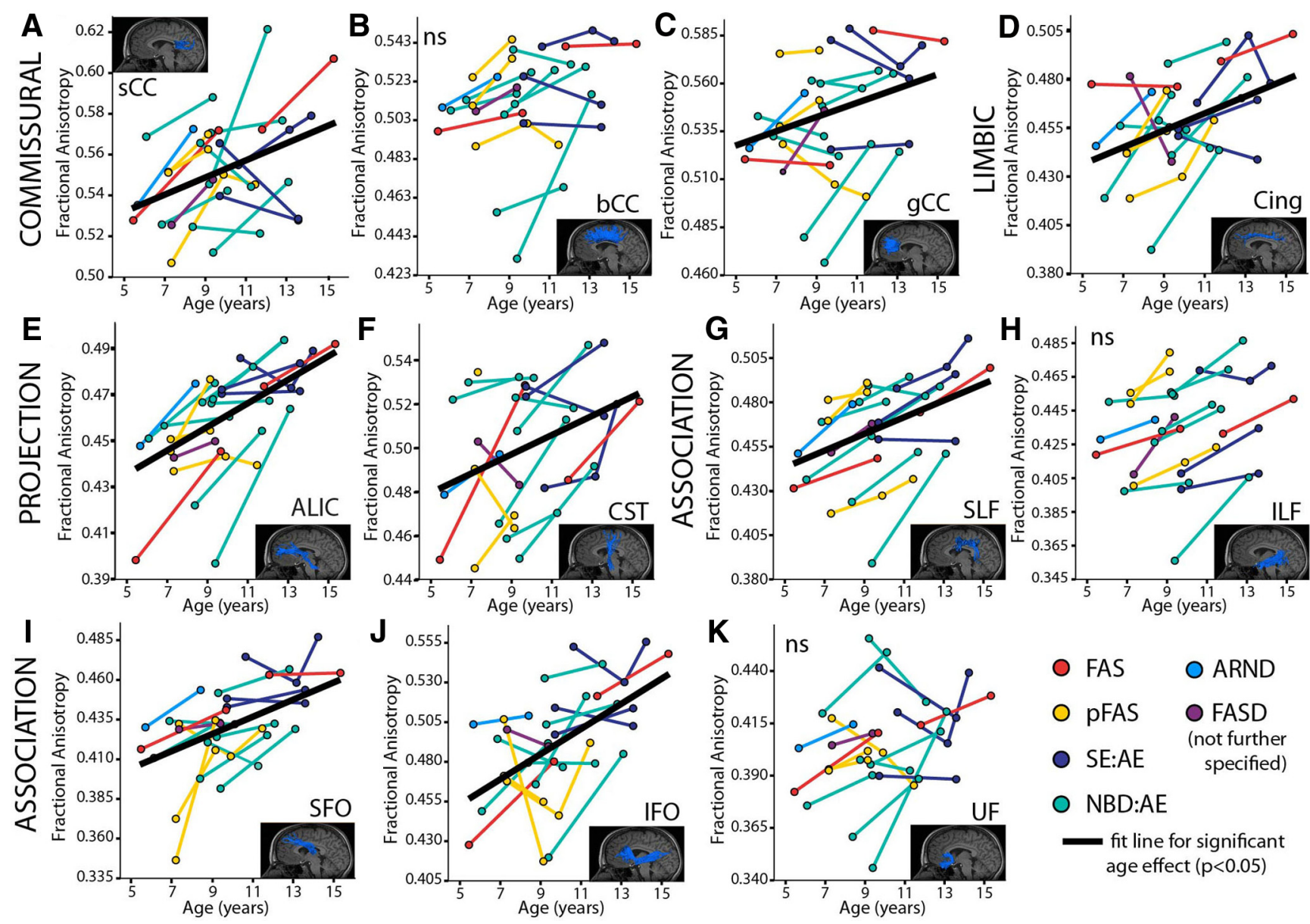

O NBD:AE

fit line for significant age effect $(p<0.05)$

Figure 3. FA of 11 major white matter tracts $(\boldsymbol{A}-\boldsymbol{K})$ in the FASD group $(n=17)$; colors indicate diagnostic categories under the FASD umbrella. Mixed-models analysis shows $8 / 11$ tracts had age-related increases of FA (as shown by best fit lines) with the exception of the bCC $(\boldsymbol{B}), \operatorname{ILF}(\boldsymbol{H})$, and UF $(\boldsymbol{K})$. Increases of FA are expected over this age range in typical development.

matter $(p=0.007)$, white matter $(p=0.036)$, thalamus $(p=$ $0.007)$, putamen $(p=0.040)$, and globus pallidus $(p=0.007)$ volumes remained significantly reduced in the FASD group.

Significant age-related increases of total brain $(p=0.008$, $2 \%)$, white matter $(p<0.001,10 \%)$, globus pallidus $(p=0.046$, $1 \%$ ), and amygdala ( $p=0.036,3 \%)$ volumes were found in the control but not FASD group. The only significant effect of age on volume found in the FASD group was cortical gray matter $(p=$
$0.042-4 \%$; Table 3). Despite these differences, mixed models analysis did not reveal significantly different proportions of subjects who underwent increases, no change, or decreases in volume between scans in the FASD versus control groups (Fig. 2).

Tractography

Significant main effects of group indicate lower FA of the SFO $(p=0.015)$ and MD of the genu $(p=0.044)$ in the FASD 

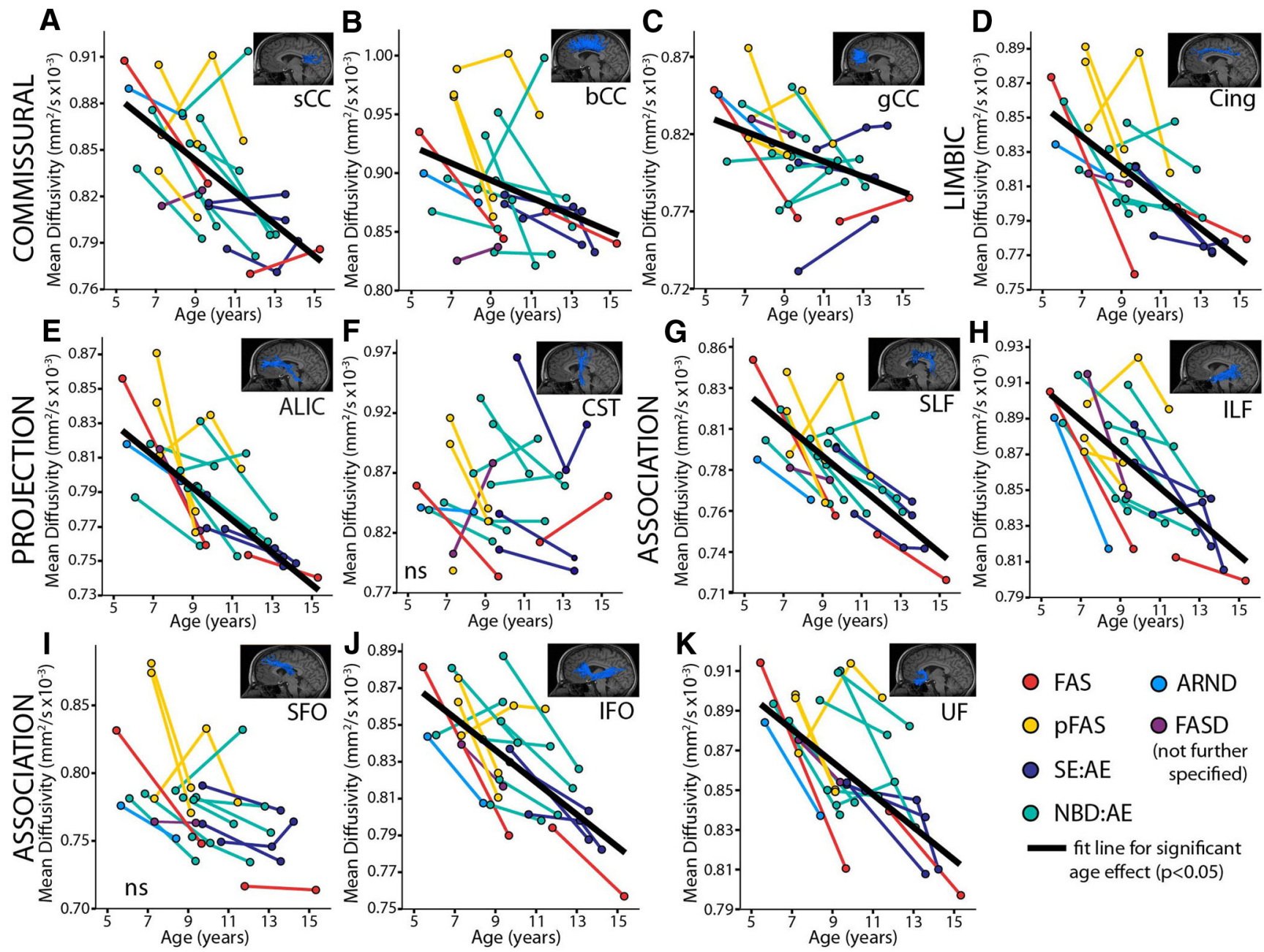

Figure 4. MD of 11 major white matter tracts $(\boldsymbol{A}-\boldsymbol{K})$ in the FASD group $(n=17)$; colors indicate diagnostic categories under the FASD umbrella. Mixed-models analysis shows $9 / 11$ tracts had significant age-related decreases of MD (as shown by best fit lines) with the exception of the CST $(\boldsymbol{F})$ and SFO $(\boldsymbol{I})$. Decreases of MD are expected over this age range in healthy development.

group compared with controls (Table 4). When separated by scan, MD of the UF was lower in FASD than controls at scan 2 but not scan 1 .

Significant age-related increases of FA $(p<0.05)$ were found in $8 / 11$ tracts in the FASD group and 11/11 tracts in the control group (Table 4; Fig. 3). The ILF, UF, and bCC did not show significant effects of age in the FASD group. Likewise, significant age-related decreases of MD $(p<0.05)$ were found in $9 / 11$ and $7 / 11$ white matter tracts in FASD and control groups, respectively (Table 4; Fig. 4); with the exception of SFO and CST in both groups and bCC and IFO in the control group.

Mixed-models analysis revealed three significant age-bygroup interactions: $\mathrm{MD}$ of the $\mathrm{SFO}(p=0.038)$, IFO $(p=0.011)$, and SLF $(p=0.034)$ (Fig. 5). In all three tracts, MD decreased more between scans in the FASD than control group. Further analysis of $\lambda_{\perp}$ and $\lambda_{/ /}$in these tracts revealed age-by-group interactions of $\lambda_{\perp}$ for the SFO $(p=0.027)$ and IFO $(p=0.030)$, with $\lambda_{\perp}$ decreasing more steeply in the FASD group in both tracts. No interactions were observed for $\lambda_{\perp}$ or $\lambda_{/ /}$of the SLF.

Chi-squared analysis of the proportion of subjects with increases/decreases/no change in either FA or MD between scans revealed significant group differences in MD of the IFO and UF $(p=0.046$ and $p=0.003$, respectively) and FA of the genu $(p=$ 0.011; Fig. 5). For the IFO and UF, more subjects in the FASD group underwent decreases of MD between scans and more con- trols showed no change between scans; for the genu most control subjects underwent no change or FA increases between scans, whereas more FASD participants underwent FA decreases between scans.

\section{Brain-behavior relationships}

Three significant correlations between change in MD and change in cognitive score between scans were found after correcting both variables for mean age and time between scans (Fig. 6). $\Delta \mathrm{MD}$ in the SLF and SFO negatively correlated with $\Delta$ WRMT-R Word ID scores in the FASD group ( $p=0.003$ and $p=0.001$, respectively), such that greater reductions of MD corresponded to larger gains in reading performance between scans. Equivalent Word ID correlations were not observed in the control group. In addition, $\triangle \mathrm{MD}$ in the SFO negatively correlated with $\triangle \mathrm{CREVT}$ receptive vocabulary $(p=0.028)$ in the FASD group, where subjects with the greatest reductions in MD had the largest gains in receptive vocabulary score between scans (note CREVT was not administered to controls). There were no significant correlations between change in cognition and change in volumes.

\section{Discussion}

This study reports the first longitudinal DTI investigation of FASD, finding regional differences in brain development compared with healthy controls. Age related increases of FA and de- 

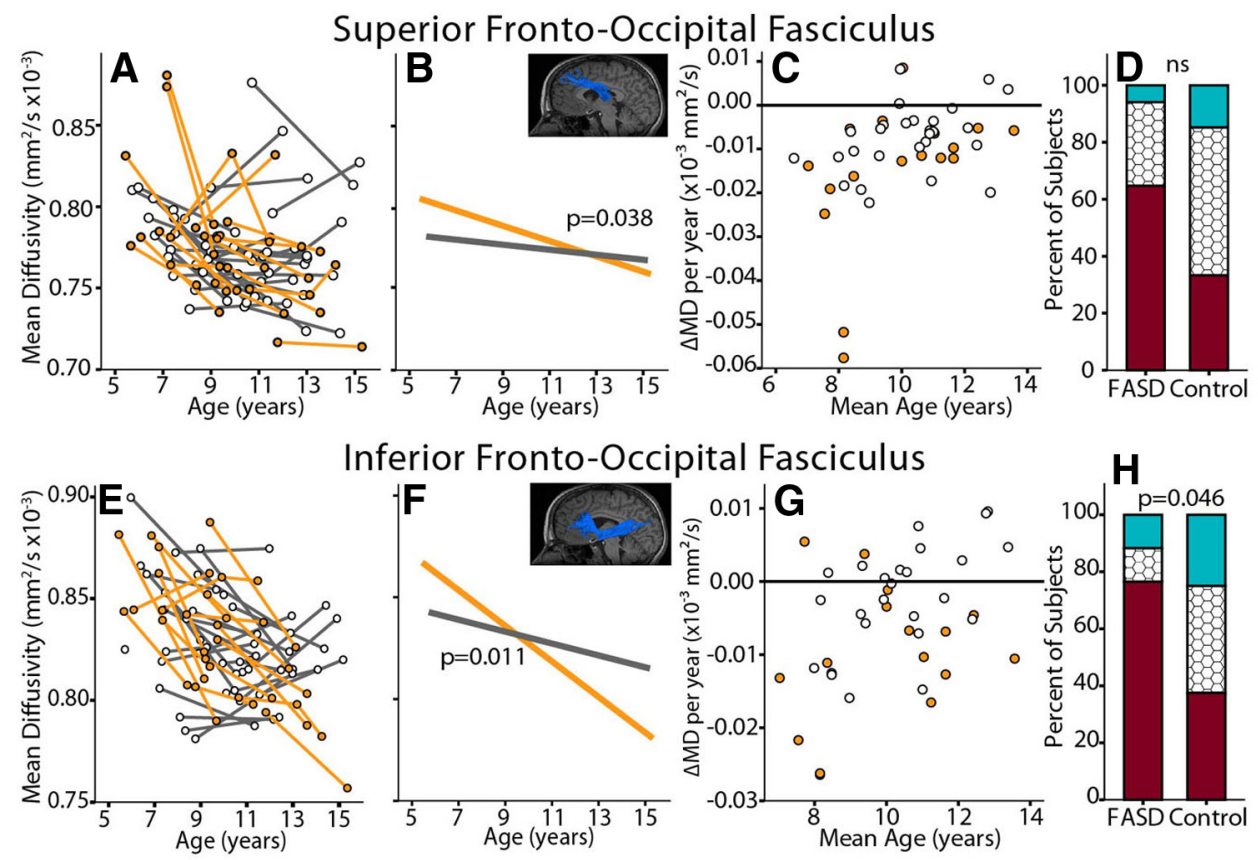

Inferior Fronto-Occipital Fasciculus
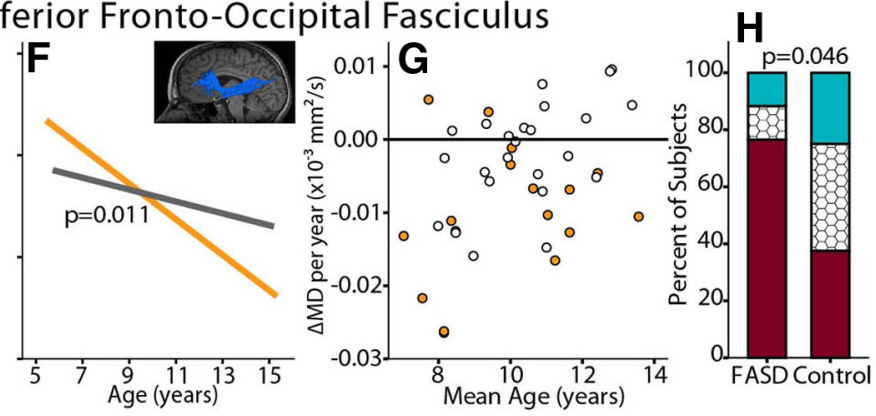

\section{Superior Longitudinal Fasciculus}
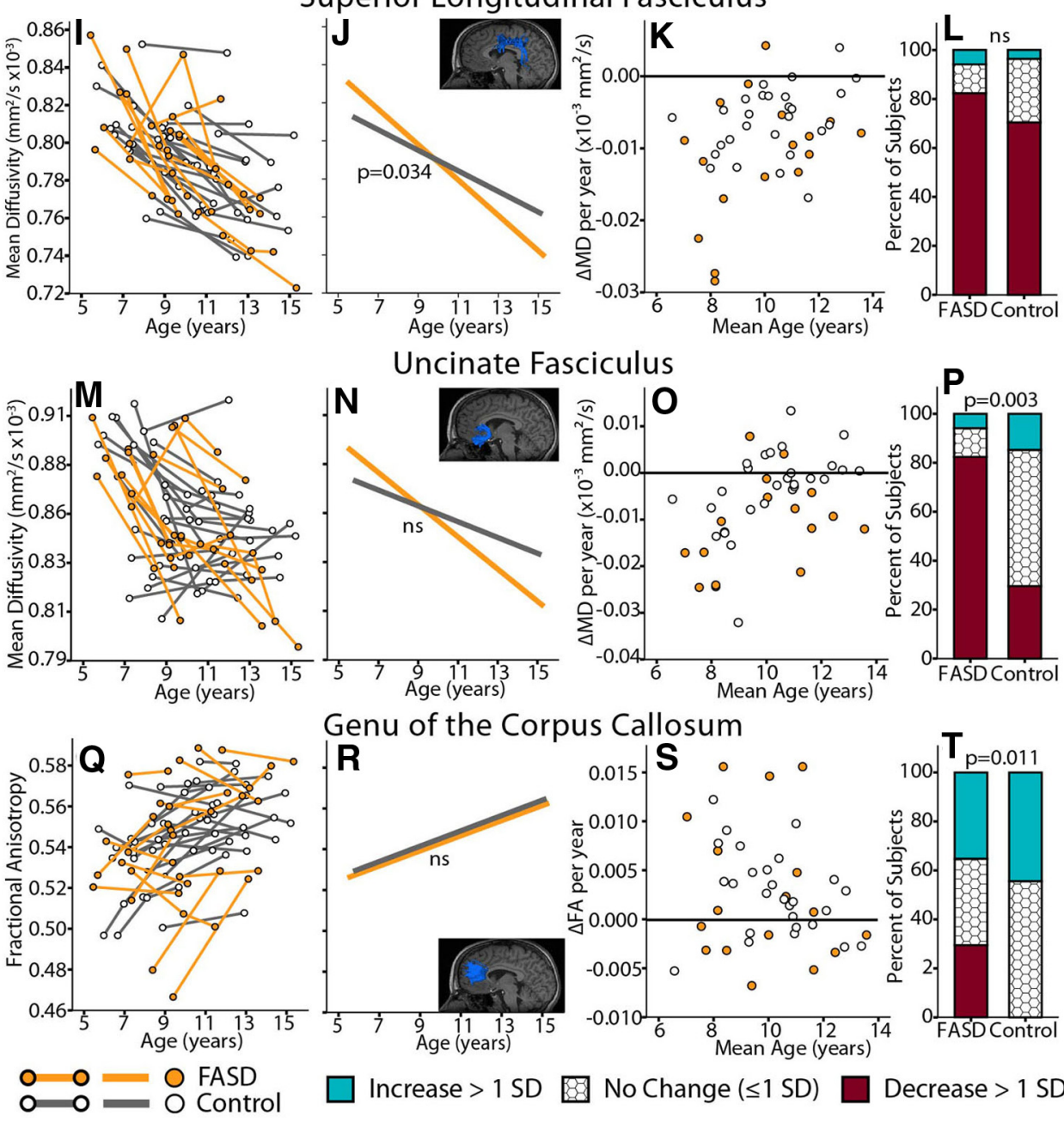

Genu of the Corpus Callosum
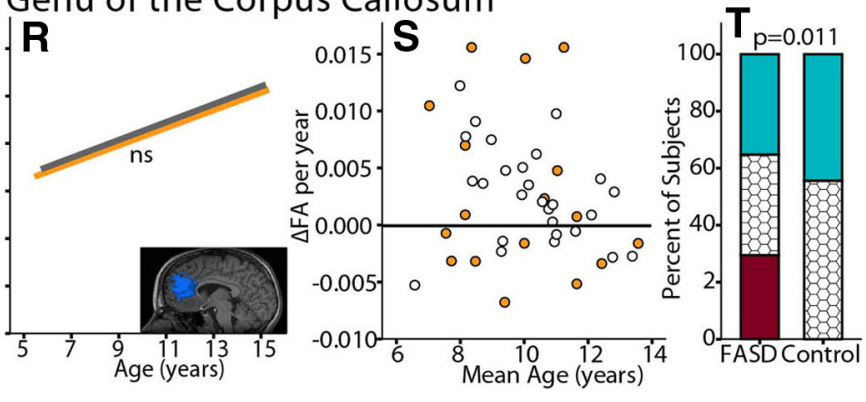

Increase $>1$ SD

No Change ( $\leq 1 \mathrm{SD}$ )

Decrease $>1 \mathrm{SD}$

Figure 5. Trajectory differences of diffusion parameters (MD or FA) with age between FASD $(n=17)$ and control ( $n=27)$ groups. Only tracts with significant age-by-group interaction in mixed-models, or significant difference in $\chi^{2}$ analysis are shown. Notably, all five tracts form frontal connections. For each tract, individual subject trajectories are shown by group in the first column (FASD orange; controls gray), followed by interaction fit lines from mixed models analysis indicating age-by-group interactions, $\triangle M D$ or $\Delta F A /$ year $\left[\left(M_{2}\right.\right.$ or $\left.F A_{2}\right)-\left(M D_{1}\right.$ or $\left.F A_{1}\right) /$ time between scans] by group, and finally bar graphs indicating the proportion of subjects in each group who underwent increases, decreases, or no change in MD or FA between scans (as determined by our established SDs for each tract, see Materials and Methods). The FASD group shows greater reductions of MD between time points than controls in the top four tracts, whereas the fifth tract $(\mathrm{gCC})$ shows more FASD participants with decreases of FA between scans than controls. 
creases of MD between scans were observed for most white matter tracts in the FASD group, in agreement with typical brain development; however, significant age-by-group interactions indicate differences in the rate of change between groups for 3 of 5 major association fibers: superior fronto-occipital, superior longitudinal, and inferior fronto-occipital fasciculi. Altered trajectories of neurodevelopment during this critical 5-15 year old period, particularly in frontal lobe connections, may further compound existing deficits and contribute to high rates of secondary disabilities that emerge during adolescence in FASD (Streissguth et al., 1991).

Cross-sectional DTI studies show group differences of FA and MD in numerous white matter tracts among individuals with prenatal alcohol exposure relative to controls (for review, see Wozniak and Muetzel, 2011). Our longitudinal analysis demonstrates relatively greater change (steeper decreases) of MD with age in the FASD group for the SFO, IFO, and SLF; changes typical of earlier childhood in healthy subjects (Lebel and Beaulieu, 2011). Greater reductions of MD may reflect delayed compensation or more stepwise progression of underlying cellular events than expected of healthy development. For example, prenatal alcohol exposure has been shown to reduce myelination in animal models (Phillips, 1989; Ozer et al., 2000). Age-by-group interactions of $\lambda_{\perp}$ in the IFO and SFO (with greater decreases between scans in the FASD group) suggest delayed myelination as a possible mechanism underlying greater MD decreases in these tracts, in keeping with Shiverer mice studies linking increased myelination with reductions of both $\lambda_{\perp}$ and MD (Song et al., 2002; Nair et al., 2005).

Interestingly, a post hoc comparison of $\triangle \mathrm{MD}$ between the "more severe" (FAS, pFAS, SE:AE) versus "less severe" (NBD: AE, ARND, FASD not further specified) FASD diagnoses and controls revealed a pattern in the IFO whereby the more severe group underwent the largest changes, followed by the less severe FASD group, and then controls (Fig. 7). A similar trend was observed in the SFO, SLF, and UF (data not shown) despite comparable cognitive profiles (at the time of study participation) between more versus less severe subgroups (scan 1: reading $92 \pm 13$ versus $94 \pm 8$, math $91 \pm 16$ versus $89 \pm 17$, scan 2 : reading $97 \pm$ 6 versus $88 \pm 22$, math $90 \pm 7$ versus $89 \pm 13$, IQ $99 \pm 15$ versus $98 \pm 15)$. Of note, a diagnosis of FAS or pFAS requires the presence of characteristic facial dysmorphology, which is associated with alcohol exposure during a critical period in the first trimester (Sulik et al., 1981) and has been correlated with structural brain abnormalities (Astley et al., 2009a; Lebel et al., 2012; Roussotte et al., 2012). Children with more severe diagnoses in this study appear to undergo the largest diffusion changes across this age range, which may relate to timing of gestational exposure or degree of initial injury, among other variables.

\section{Superior Fronto-Occipital Fasciculus}
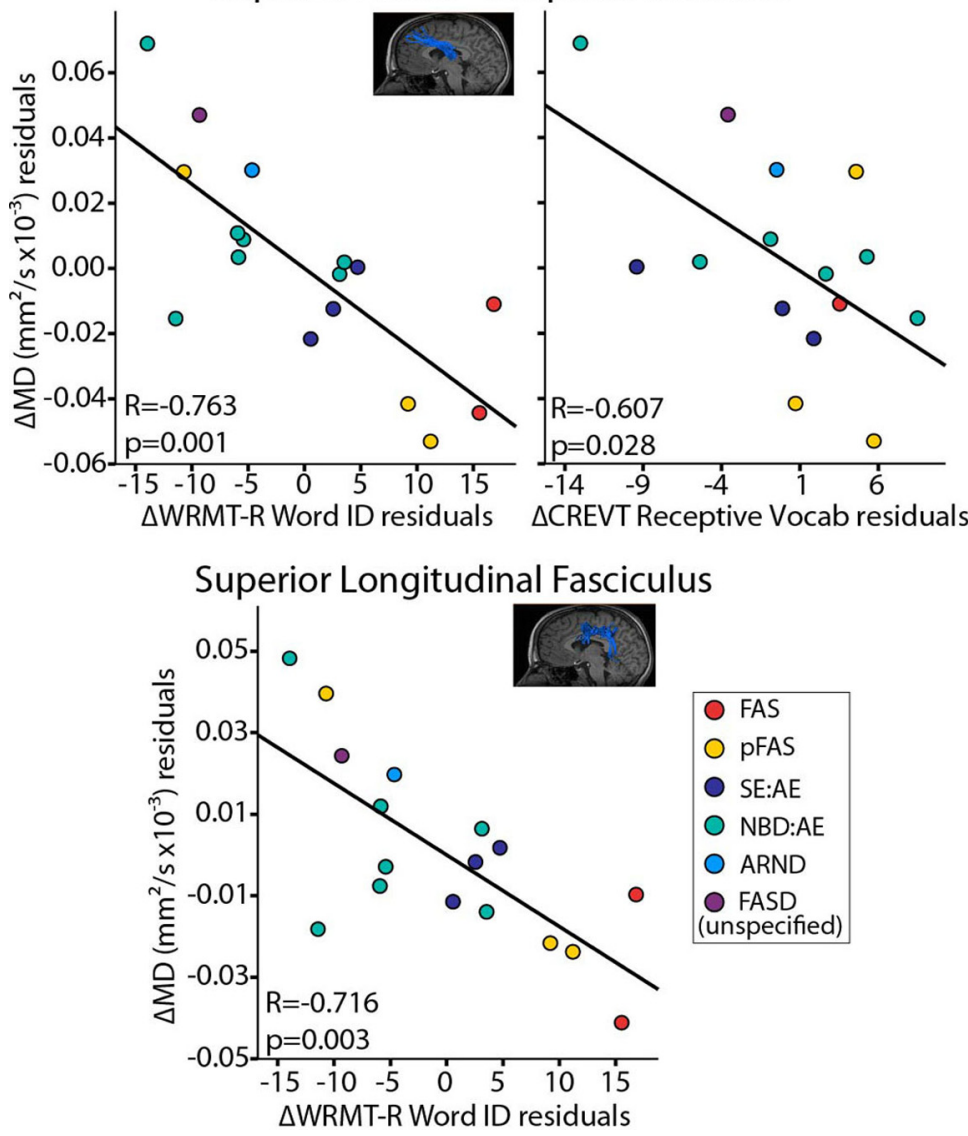

Figure 6. DTI parameter cognitive correlations in the FASD group ( $n=17$ ). Graphs show $\Delta$ MD plotted against $\Delta$ cognitive scores (after correcting both variables for mean age and time between scans). Reductions of MD in the SLF and significantly correlated with increases in performance on a word reading test (Word ID). In addition, decreases of MD in the SFO correlated with increases in performance on receptive vocabulary (CREVT). Corresponding correlations of $\Delta M D$ with $\triangle$ WRMT-R Word ID were not observed in the control group.

All five of the tracts with either significant age-by-group interactions or $\chi^{2}$ differences in the proportion of subjects with $\Delta \mathrm{FA}$ or $\Delta \mathrm{MD}$ (i.e., SLF, SFO, IFO, UF, and genu; Fig. 5) form frontal lobe connections as part of their anatomical course. Frontal lobe abnormalities are reported in FASD (for review, see Norman et al., 2009), and may relate to impaired decision making. The frontal lobes undergo protracted maturation in healthy development (Jernigan and Tallal, 1990; Pfefferbaum et al., 1994; Reiss et al., 1996; Giedd et al., 1999), with frontal association fibers showing continued development into early adulthood according to longitudinal DTI (Lebel and Beaulieu, 2011), leaving them susceptible to environmental influence and epigenetic changes that may play a role in abnormal adolescent brain development in FASD.

This FASD group was impaired on a number of academic and executive functioning domains at both time points, despite average IQ scores (measured in 53\% of the FASD sample). Longitudinal increases in raw cognitive scores (albeit without changes in age-corrected standard scores) suggest that the FASD group made cognitive gains at a typical rate with age, while still performing below average. Negative correlations of $\Delta \mathrm{MD}$ in the SLF with increased gains in Word ID score fit with the putative role of this tract in language functioning (Steinbrink et al., 2008; Brauer et al., 2011; Hoeft et al., 2011), but have not been previously demonstrated in FASD. Correlations between $\triangle \mathrm{MD}$ in the SFO with 


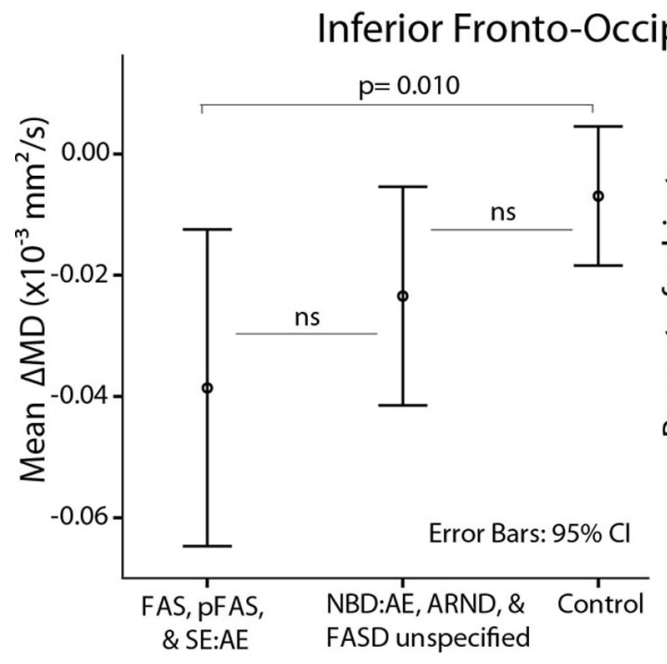

Figure 7. Change in MD of the IFO between scans by diagnostic subgroup. Relatively greater $\triangle M D$ between scans is observed in the more severe diagnostic categories (FAS, pFAS, SE:AE, $n=8$ ) followed by less severe (NBD:AE. ARND, FASD unspecified, $n=$ 9 ) and finally controls $(n=27)$, despite similar mean ages $(10.3 \pm 2.3 ; 9.4 \pm 1.5 ; 10.3 \pm 1.7)$, mean years between scans $(3.4 \pm$ $0.9 ; 3.0 \pm 0.5 ; 3.6 \pm 0.9)$, and mean reading standard scores $(95 \pm 10 ; 91 \pm 15 ; 112 \pm 13)$ and math scores $(91 \pm 12 ; 89 \pm 15$; $\mathrm{n} / \mathrm{a}$ ) among these three groups, respectively.

both increased reading and receptive vocabulary score also suggest a role for this tract in language development. Correlations with cognitive improvement provide evidence that steep decreases of MD in these tracts are functionally relevant in FASD; it is notable that SFO and SLF are the last association tracts to reach an MD plateau in healthy development (Lebel et al., 2008a) and thus may be even further delayed in FASD.

Given that microcephaly is a hallmark feature used to diagnose FASD, it is not surprising that smaller brain volumes are noted in almost every structural MRI study including this one. Of note, the largest group difference was observed in the caudate ( $18 \%$ reduction in FASD), in agreement with two recent studies showing $\sim 20 \%$ reductions of caudate volume (Astley et al., 2009b; Fryer et al., 2012); though these studies also demonstrate correlations with neurocognitive scores (Fryer et al., 2012) and diagnosis severity (Astley et al., 2009b). Reductions in cortical gray matter, white matter, thalamus, globus pallidus, and putamen volumes in this study remained significant after controlling for total brain volume, and have been reported as disproportionately reduced in other samples (Archibald et al., 2001; Roussotte et al., 2011). Age-related increases in total brain, white matter, globus pallidus, and amygdala volumes were observed in the control group in agreement with typical development (Giedd et al., 1997, 1999; Lenroot et al., 2007; Brain Development Cooperative Group, 2012), but lack of significant age effects in the FASD group suggests delayed growth (though note age-by-group interactions were not significant). Nonetheless, persistent volume reductions compared with controls at both scans confirm that volume reductions are not mitigated during development. A recent longitudinal study of cortical volume development in 70 subjects with prenatal alcohol exposure found reduced cortical plasticity (Lebel et al., 2012), revealing age-by-group interactions of volume trajectory with alcohol-exposed participants showing flatter developmental curves than controls. Notably, smaller volume changes between scans were associated with lower IQ and greater facial dysmorphology at scan 1 .

Many children with FASD experience both prenatal alcohol exposure and adverse postnatal environments, in some cases in- cluding abuse, neglect, and multiple home placements, which likely compound alcohol-related brain abnormalities and may even act through independent mechanisms (Streissguth et al., 2004; McCrory et al., 2010). In addition to often unknown variability in the degree and timing of prenatal alcohol exposure, these other adverse life experiences complicate associations between prenatal alcohol exposure and adolescent brain development in human studies (as opposed to well controlled preclinical animal models). This study only included children in currently stable home placements (those who had moved placements between scans could not be located for follow-up) and required participants to tolerate the MRI scanner and provide adequate data at least twice, potentially excluding more severely affected children. We found no difference between groups on annual household income or primary caregiver education, suggesting approximately matched socioeconomic status at the time of MRI study participation; however, we cannot rule out the influence of numerous other possible disparities, including adverse early life experience, polysubstance exposures, and unknown genetic factors that could influence sensitivity to alcohol-induced brain injury (Warren and Li, 2005). Ethnicity was not balanced between groups in this study, which may also confer systematic genetic differences, though brain volume reductions of our sample are on par with those of larger more ethnically diverse samples (Astley et al., 2009a). Finally, the relatively small sample size of this study required that we approximate a linear fit to the data despite converging evidence that development is nonlinear (Giedd et al., 1999; Lebel et al., 2008a), and combining left and right tracts may have masked hemispheric asymmetries. Nonetheless, the longitudinal design of this study overcomes many limitations of previous studies, as it identifies changes within individuals, increasing power and reducing the effects of subject variation. Future studies should aim to test trajectory differences between FASD diagnostic subgroups as well as other environmental and subject variables including ethnicity, age at diagnosis, history of abuse and home stability.

In this novel longitudinal DTI study over the ages of 5-15 years, participants with FASD demonstrated increases of FA and reductions of MD associated with typical white matter development, albeit with regional differences in rate and magnitude. Steeper decreases of MD in three frontal association tracts in FASD may reflect delayed white matter development, but may also suggest compensatory plasticity. Participants with FASD had persistently smaller brain volumes than controls, confirming that these reductions are not mitigated nor exacerbated during development. Observed deviations from the typical trajectory of neurodevelopment during childhood and adolescence may underlie secondary deficits that emerge during this critical period.

\section{References}

Archibald SL, Fennema-Notestine C, Gamst A, Riley EP, Mattson SN, Jernigan TL (2001) Brain dysmorphology in individuals with severe prenatal alcohol exposure. Dev Med Child Neurol 43:148-154. CrossRef Medline Astley S (2004) Diagnostic guide for fetal alcohol spectrum disorders: the 
4-digit diagnostic code. In: Fetal alcohol syndrome diagnostic and prevention network, Ed 3. Seattle: FAS Diagnostic and Prevention Network, University of Washington.

Astley SJ, Aylward EH, Olson HC, Kerns K, Brooks A, Coggins TE, Davies J, Dorn S, Gendler B, Jirikowic T, Kraegel P, Maravilla K, Richards T (2009a) Magnetic resonance imaging outcomes from a comprehensive magnetic resonance study of children with fetal alcohol spectrum disorders. Alcohol Clin Exp Res 33:1671-1689. CrossRef Medline

Astley SJ, Olson HC, Kerns K, Brooks A, Aylward EH, Coggins TE, Davies J, Dorn S, Gendler B, Jirikowic T, Kraegel P, Maravilla K, Richards T (2009b) Neuropyschological and behavioral outcomes from a comprehensive magnetic resonance study of children with fetal alcohol spectrum disorders. Can J Clin Pharmacol 16:e178-201. Medline

Bava S, Thayer R, Jacobus J, Ward M, Jernigan TL, Tapert SF (2010) Longitudinal characterization of white matter maturation during adolescence. Brain Res 1327:38-46. CrossRef Medline

Brain Development Cooperative Group (2012) Total and regional brain volumes in a population-based normative sample from 4 to 18 years: the NIH MRI study of normal brain development. Cereb Cortex 22:1-12. CrossRef Medline

Brauer J, Anwander A, Friederici AD (2011) Neuroanatomical prerequisites for language functions in the maturing brain. Cereb Cortex 21:459-466. CrossRef Medline

Chudley AE, Conry J, Cook LL, Loock C, Rosales T, LeBlanc N (2005) Fetal alcohol spectrum disorder: Canadian guidelines for diagnosis. CMAJ 172: S1-S21. CrossRef Medline

Coles CD, Goldstein FC, Lynch ME, Chen X, Kable JA, Johnson KC, Hu X (2011) Memory and brain volume in adults prenatally exposed to alcohol. Brain Cogn 75:67-77. CrossRef Medline

Fischl B, Salat DH, Busa E, Albert M, Dieterich M, Haselgrove C, van der Kouwe A, Killiany R, Kennedy D, Klaveness S, Montillo A, Makris N, Rosen B, Dale AM (2002) Whole brain segmentation: automated labeling of neuroanatomical structures in the human brain. Neuron 33:341355. CrossRef Medline

Fryer SL, Schweinsburg BC, Bjorkquist OA, Frank LR, Mattson SN, Spadoni AD, Riley EP (2009) Characterization of white matter microstructure in fetal alcohol spectrum disorders. Alcohol Clin Exp Res 33:514-521. CrossRef Medline

Fryer SL, Mattson SN, Jernigan TL, Archibald SL, Jones KL, Riley EP (2012) Caudate volume predicts neurocognitive performance in youth with heavy prenatal alcohol exposure. Alcohol Clin Exp Res 36:1932-1941. CrossRef Medline

Giedd JN, Castellanos FX, Rajapakse JC, Vaituzis AC, Rapoport JL (1997) Sexual dimorphism of the developing human brain. Prog Neuropsychopharmacol Biol Psychiatry 21:1185-1201. CrossRef Medline

Giedd JN, Blumenthal J, Jeffries NO, Castellanos FX, Liu H, Zijdenbos A, Paus T, Evans AC, Rapoport JL (1999) Brain development during childhood and adolescence: a longitudinal MRI study. Nat Neurosci 2:861-863. CrossRef Medline

Giorgio A, Watkins KE, Chadwick M, James S, Winmill L, Douaud G, De Stefano N, Matthews PM, Smith SM, Johansen-Berg H, James AC (2010) Longitudinal changes in grey and white matter during adolescence. Neuroimage 49:94-103. CrossRef Medline

Goodlett CR, Horn KH, Zhou FC (2005) Alcohol teratogenesis: mechanisms of damage and strategies for intervention. Exp Biol Med 230:394-406. Medline

Hoeft F, McCandliss BD, Black JM, Gantman A, Zakerani N, Hulme C, Lyytinen H, Whitfield-Gabrieli S, Glover GH, Reiss AL, Gabrieli JD (2011) Neural systems predicting long-term outcome in dyslexia. Proc Natl Acad Sci U S A 108:361-366. CrossRef Medline

Hoyme HE, May PA, Kalberg WO, Kodituwakku P, Gossage JP, Trujillo PM, Buckley DG, Miller JH, Aragon AS, Khaole N, Viljoen DL, Jones KL, Robinson LK (2005) A practical clinical approach to diagnosis of fetal alcohol spectrum disorders: clarification of the 1996 institute of medicine criteria. Pediatrics 115:39-47. CrossRef Medline

Jernigan TL, Tallal P (1990) Late childhood changes in brain morphology observable with MRI. Dev Med Child Neurol 32:379-385. Medline

Lebel C, Beaulieu C (2011) Longitudinal development of human brain wiring continues from childhood into adulthood. J Neurosci 31:10937-10947. CrossRef Medline

Lebel C, Walker L, Leemans A, Phillips L, Beaulieu C (2008a) Microstruc- tural maturation of the human brain from childhood to adulthood. Neuroimage 40:1044-1055. CrossRef Medline

Lebel C, Rasmussen C, Wyper K, Walker L, Andrew G, Yager J, Beaulieu C (2008b) Brain diffusion abnormalities in children with fetal alcohol spectrum disorder. Alcohol Clin Exp Res 32:1732-1740. CrossRef Medline

Lebel C, Roussotte F, Sowell ER (2011) Imaging the impact of prenatal alcohol exposure on the structure of the developing human brain. Neuropsychol Rev 21:102-118. CrossRef Medline

Lebel C, Mattson SN, Riley EP, Jones KL, Adnams CM, May PA, Bookheimer SY, O'Connor MJ, Narr KL, Kan E, Abaryan Z, Sowell ER (2012) A longitudinal study of the long-term consequences of drinking during pregnancy: heavy in utero alcohol exposure disrupts the normal processes of brain development. J Neurosci 32:15243-15251. CrossRef Medline

Leemans A, Jeurissen B, Sijbers J, Jones D (2009) ExploreDTI: a graphical toolbox for processing, analyzing, and visualizing diffusion MR data. In: 17th Annual Meeting of International Society of Magnetic Resonance Med, Hawaii, 2009, p 3537

Lenroot RK, Gogtay N, Greenstein DK, Wells EM, Wallace GL, Clasen LS, Blumenthal JD, Lerch J, Zijdenbos AP, Evans AC, Thompson PM, Giedd JN (2007) Sexual dimorphism of brain developmental trajectories during childhood and adolescence. Neuroimage 36:1065-1073. CrossRef Medline

Li LC, Coles CD, Lynch ME, Hu X (2009) Voxelwise and skeleton-based region of interest analysis of fetal alcohol syndrome and fetal alcohol spectrum disorders in young adults. Hum Brain Mapp 30:3265-3274. CrossRef Medline

Ma XY, Coles CD, Lynch ME, LaConte SM, Zurkiya O, Wang DL, Hu XP (2005) Evaluation of corpus callosum anisotropy in young adults with fetal alcohol syndrome according to diffusion tensor imaging. Alcohol Clin Exp Res 29:1214-1222. CrossRef Medline

Mattson SN, Riley EP, Gramling L, Delis DC, Jones KL (1998) Neuropsychological comparison of alcohol-exposed children with or without physical features of fetal alcohol syndrome. Neuropsychology 12:146-153. CrossRef Medline

May PA, Gossage JP (2001) Estimating the prevalence of fetal alcohol syndrome: a summary. Alcohol Res Health 25:159-167. Medline

May PA, Gossage JP, Kalberg WO, Robinson LK, Buckley D, Manning M, Hoyme HE (2009) Prevalence and epidemiologic characteristics of FASD from various research methods with an emphasis on recent inschool studies. Dev Disabil Res Rev 15:176-192. CrossRef Medline

McCrory E, De Brito SA, Viding E (2010) Research review: the neurobiology and genetics of maltreatment and adversity. J Child Psychol Psychiatry 51:1079-1095. CrossRef Medline

Nair G, Tanahashi Y, Low HP, Billings-Gagliardi S, Schwartz WJ, Duong TQ (2005) Myelination and long diffusion times alter diffusion-tensor-imaging contrast in myelin-deficient shiverer mice. Neuroimage 28:165-174. CrossRef Medline

Nardelli A, Lebel C, Rasmussen C, Andrew G, Beaulieu C (2011) Extensive deep gray matter volume reductions in children and adolescents with fetal alcohol spectrum disorders. Alcohol Clin Exp Res 35:1404-1417. CrossRef Medline

Norman AL, Crocker N, Mattson SN, Riley EP (2009) Neuroimaging and fetal alcohol spectrum disorders. Dev Disabil Res Rev 15:209-217. CrossRef Medline

Ozer E, Sarioglu S, Güre A (2000) Effects of prenatal ethanol exposure on neuronal migration, neuronogenesis and brain myelination in the mice brain. Clin Neuropathol 19:21-25. Medline

Pfefferbaum A, Mathalon DH, Sullivan EV, Rawles JM, Zipursky RB, Lim KO (1994) A quantitative magnetic-resonance-imaging study of changes in brain morphology from infancy to late adulthood. Archives of Neurology 51:874-887. CrossRef Medline

Phillips DE (1989) Effects of limited postnatal ethanol exposure on the development of myelin and nerve-fibres in rat optic-nerve. Exp Neurol 103:90-100. CrossRef Medline

Reiss AL, Abrams MT, Singer HS, Ross JL, Denckla MB (1996) Brain development, gender and IQ in children: a volumetric imaging study. Brain 119:1763-1774. CrossRef Medline

Roussotte FF, Sulik KK, Mattson SN, Riley EP, Jones KL, Adnams CM, May PA, O'Connor MJ, Narr KL, Sowell ER (2012) Regional brain volume reductions relate to facial dysmorphology and neurocognitive function in fetal alcohol spectrum disorders. Hum Brain Mapp 33:920-937. CrossRef Medline 
Roussotte F, Soderberg L, Sowell E (2010) Structural, metabolic, and functional brain abnormalities as a result of prenatal exposure to drugs of abuse: evidence from neuroimaging. Neuropsychol Rev 20:376-397. CrossRef Medline

Song SK, Sun SW, Ramsbottom MJ, Chang C, Russell J, Cross AH (2002) Dysmyelination revealed through MRI as increased radial (but unchanged axial) diffusion of water. Neuroimage 17:1429-1436. CrossRef Medline

Sowell ER, Johnson A, Kan E, Lu LH, Van Horn JD, Toga AW, O’Connor MJ, Bookheimer SY (2008) Mapping white matter integrity and neurobehavioral correlates in children with fetal alcohol spectrum disorders. J Neurosci 28:1313-1319. CrossRef Medline

Spottiswoode BS, Meintjes EM, Anderson AW, Molteno CD, Stanton ME, Dodge NC, Gore JC, Peterson BS, Jacobson JL, Jacobson SW (2011) Diffusion tensor imaging of the cerebellum and eyeblink conditioning in fetal alcohol spectrum disorder. Alcohol Clin Exp Res 35:2174-2183. CrossRef Medline

Steinbrink C, Vogt K, Kastrup A, Müller HP, Juengling FD, Kassubek J, Riecker A (2008) The contribution of white and gray matter differences to developmental dyslexia: insights from DTI and VBM at 3.0 T. Neuropsychologia 46:3170-3178. CrossRef Medline

Streissguth AP, Aase JM, Clarren SK, Randels SP, LaDue RA, Smith DF (1991) Fetal alcohol syndrome in adolescents and adults. JAMA 265:1961-1967. CrossRef Medline
Streissguth AP, Bookstein FL, Barr HM, Sampson PD, O’Malley K, Young JK (2004) Risk factors for adverse life outcomes in fetal alcohol syndrome and fetal alcohol effects. J Dev Behav Pediat 25:228-238. CrossRef Medline

Sulik KK, Johnston MC, Webb MA (1981) Fetal alcohol syndromeembryogenesis in a mouse model. Science 214:936-938. CrossRef Medline

Wakana S, Jiang H, Nagae-Poetscher LM, van Zijl PC, Mori S (2004) Fiber tract-based atlas of human white matter anatomy. Radiology 230:77-87. CrossRef Medline

Warren KR, Li TK (2005) Genetic polymorphisms: impact on the risk of fetal alcohol spectrum disorders. Birth Defects Res A Clin Mol Teratol 73:195-203. CrossRef Medline

Wozniak JR, Muetzel RL (2011) What does diffusion tensor imaging reveal about the brain and cognition in fetal alcohol spectrum disorders? Neuropsychol Rev 21:133-147. CrossRef Medline

Wozniak JR, Mueller BA, Chang PN, Muetzel RL, Caros L, Lim KO (2006) Diffusion tensor imaging in children with fetal alcohol spectrum disorders. Alcohol Clin Exp Res 30:1799-1806. CrossRef Medline

Wozniak JR, Muetzel RL, Mueller BA, McGee CL, Freerks MA, Ward EE, Nelson ML, Chang PN, Lim KO (2009) Microstructural corpus callosum anomalies in children with prenatal alcohol exposure: an extension of previous diffusion tensor imaging findings. Alcohol Clin Exp Res 33: 1825-1835. CrossRef Medline 